\title{
Management of Dehydration in Children: Effect of Nursing Protocol
}

\author{
Sohair M. khider, Wafaa, E. Ouda, Hayam, R. Tantawi \\ Pediatrics Nursing Department, Ain Shams University
}

\begin{abstract}
Introduction: Nursing protocols in management of dehydration in children has improved the quality and consistency of care for the children with dehydration. Aim of the Study: The present study aimed to investigate the effect of nursing protocol in management of dehydration in children. Study Design: A quasi- experimental design was utilized. Setting: The study was carried out at Pediatric Emergency and Medical Departments/Pediatric Children's Hospital, affiliated to Ain Shams University Hospitals. Subjects: The study included 30 nurses caring for children suffering from dehydration. Also, the study sample involved 30 children diagnosed with dehydration and their parents in the previously mentioned settings. Tools of the Study: The involved children and their parents' assessment sheet, nurses' questionnaire sheet for knowledge assessment pre- and post-implementation of nursing protocol, observational checklists and nursing protocol in management of dehydration in children. Results: It was clear that the majority of the studied nurses had satisfactory knowledge and competent practices regarding management of dehydration in children-post implementation of nursing protocol. There was a statistically significant difference between total nurses' knowledge and practice. Conclusion: Implementation of nursing protocol had a positive effect on the improvement of nurses' knowledge and practice regarding care of children suffering from dehydration. Recommendations: Raising awareness of nurses regarding nursing protocol in management of dehydration in children.
\end{abstract}

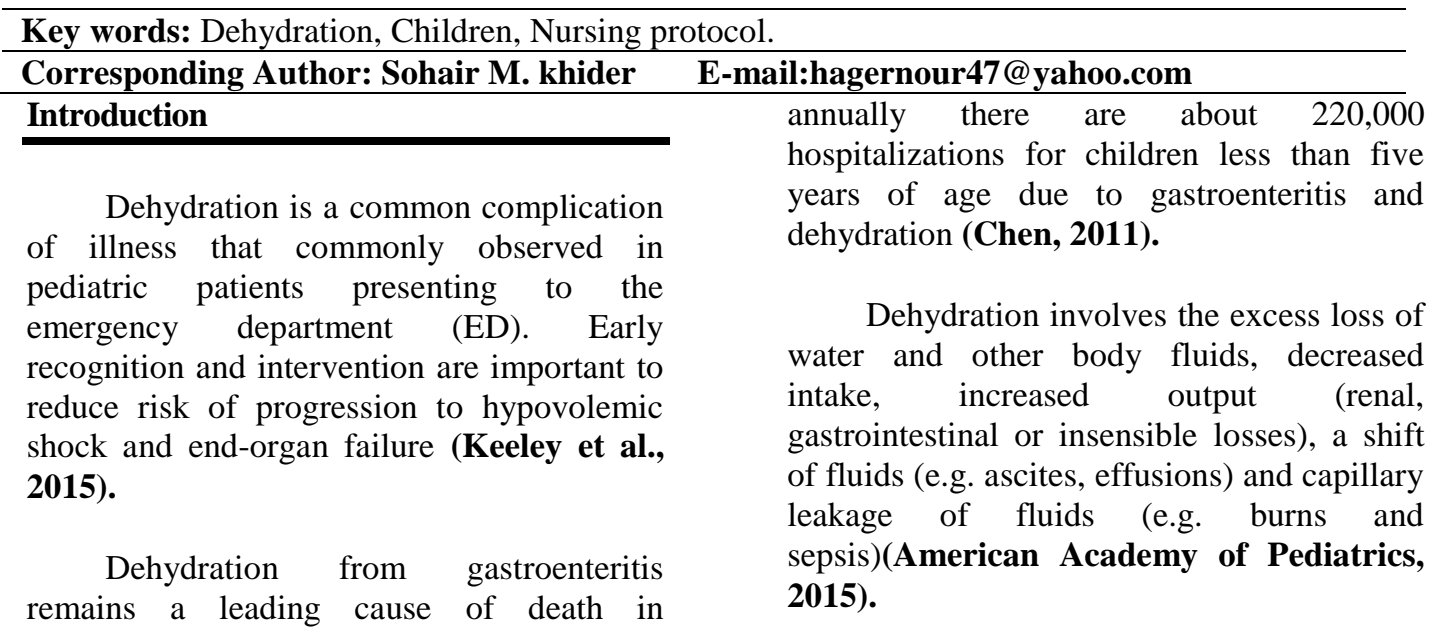
developing countries. In the United States, 
Rehydration with oral rehydration solution (ORS) is highly supported by (World Health Organization, the Centers for Disease Control and Prevention (CDC), the American Academy of Pediatrics (AAP) and the European Society of Pediatric Gastroenterology and Nutrition (ESPGAN), 2011)for children with mild to moderate dehydration and reserving intravenous (IV) fluids for children with severe dehydration.

Nursing protocols in management of dehydration in children are considered one of the most promising and effective advances for defining and improving the quality of care. However, their development, dissemination and implementation in practice are rarely straight forward. The use of protocols also known as standing orders, preprinted order sets, advanced nursing interventions and computerized order sets has been recognized as a method of enhancing safety, while expediting pediatric patient care (Retezar et al., 2011).

Also, nursing protocol in management of dehydration children are institution-based guidelines, developed for dehydration in children or chief complaints that allow the nurse to initiate diagnostic tests and interventions regarding child suffering from dehydration evaluated by health care provider. Early implementation of nursing protocols for dehydration has been reported to decrease pediatric patient length of stay in the emergency department(Stauber, 2013).

The integrated management of childhood illness (IMCI) using nursing protocol for the management of dehydration in children with dehydration includes three plans such as plan (A) to children with mild dehydration or to those who have been successfully rehydrated, plan (B) is for children with moderate dehydration and plan (C) is for severe dehydration(Yu et al., 2011).
Emergency nurses in pediatric care setting should be trained on using nursing protocol, which also contain details of practical procedures for management of different degrees of dehydration including, administration of oral rehydration therapy and intravenous fluid therapy. Nurses involved in pediatric care settings should be able to demonstrate continuing professional development in the specialty by attendance at local meetings, suitable training courses and national meetings(Bonilla-Felix et al., 2011).Hospitals must be able to demonstrate the necessary professional and technical infrastructure together with protocols to access specialist services provided elsewhere. However, each pediatric care setting should be fully complied with clinical guidelines, quality assurance, follow up of high risk survivors, monitoring services provision and access for training and continuing education (Harmon et al., 2013).

\section{Significance of the Study}

Dehydration is a frequent reason for emergency room visits and affects at least 2 million children annually. Frequently caused by gastroenteritis, dehydration may result in serious morbidity and mortality. Gastroenteritis and dehydration account for $30 \%$ of all infants and toddler deaths worldwide and approximately 300 deaths annually in the U.S. Gastroenteritis alone results in 1.9 million pediatric deaths annually or $19 \%$ of all deaths under the age of 5(Pringle et al., 2011).

In Egypt, deaths among children under 5 years due to diarrheal diseases and dehydration accounted to $3 \%$ of all causes of death. Nursing protocol for the management of diarrheal illnesses and dehydration have been refined as new strategies for prevention and control of this major health problem (Sayedet al., 2014). 


\section{Aim of the study}

The current study aimed to study the effect of nursing protocol in management of dehydration in children. This aim was attained through the following objectives:

- Assessing nurses' knowledge and practice regarding nursing protocol in management of dehydration in children.

- Designing, implementing and evaluating the effectiveness of nursing protocol in management of dehydration in children.

\section{The Research Hypothesis:}

There is a positive effect of nursing protocol in management of dehydration in children.

\section{Subjects and method}

\section{Research design:}

A quasi-experimental design was utilized in this study.

\section{Setting:}

This study was conducted at Pediatric Emergency and Medical Department/Pediatric Children's Hospital affiliated to Ain Shams University Hospitals.

\section{Sampling:}

A purposive sample was used, it composed of 30 nurses, (10) from pediatric emergency department and (20) from pediatric medical department. Both genders were involved regardless their qualifications and years of experience. The study sample involved also 30 children diagnosed with dehydration and their parents in the previously mentioned settings under the following inclusion criteria:
- Confirmed diagnosis with dehydration.

- Both genders, regardless their age.

- Free from chronic illnesses and handicaps.

\section{Tools and data collection:}

I. Assessment sheet for the studied children and their parents (Appendix II) to gather data related to:

a. Demographic characteristics of children suffering from dehydration as gender, age, level of education and ranking.

b. Medical history of children suffering from dehydration as previous hospital admissions due to dehydration and type of dehydration management.

c. Characteristics of children's family as age of parents, their levels of education and jobs.

II. Questionnaire sheet for nurses to assess nurse's knowledge [pre- and post- its implementation] (Appendix II). This tool was developed by the researcher in the light of relevant references and composed of the following parts:

a. First part was concerned with characteristics of the nurses such as age, level of education, years of experience and attendance of previous training about nursing protocols for management of dehydration in children.

b. Second part was concerned with the nurses' knowledge (pre - post) nursing protocol regarding:

- Definition of dehydration in children, incidence, causes, signs and symptoms, 
degrees, types, complications, diagnosis and treatment.

- Definition of nursing protocols for management of dehydration in children, steps, aim, indications, advantages, parts and contents.

- Treatment plans for management of pediatric dehydration.

\section{Scoring system:}

Items of nurses' knowledge assessment about pediatric dehydration, nursing protocols and treatment plans for management of pediatric dehydration consisted of 100 closed ended questions. The total score was (100), and was distributed according to the importance of each item. According to nurse's responses, their knowledge scores were classified into satisfactory $(\geq 80 \%)$ and unsatisfactory $(<80$ $\%)$.

\section{Content validity:}

The questionnaire sheet was assessed and ascertained by a panel of five experts in paediatric nursing to validate its format, layout, consistency, accuracy and relevance.

\section{Observation checklists (Appendix} III):They were used to assess the nurses' practices regarding nursing protocols for management of dehydration in children (preand post-nursing protocol) as follows:

\section{1- Child's measurement checklistincluded:}

a. Infant's weight,(Cupta, 2011), to assess nurses' practice in weighing the infant pre- and post-nursing protocol that contained 7 steps.

b. Child's weight,(Skale, 2014),to assess nurses' practice in weighing the child pre- and post-nursing protocol that contained 6 steps which were checked either done correctly (2 scores) or incorrectly done (1 score) or not done (zero). The total scores were 26, then the total practice in weighing was scoredcompetent $(\geq 85 \%)$ or incompetent $(<85 \%)$.

2- Temperature measurement checklist, (Skale, 2014), consisted of 10 steps which were checked either done correctly (2 scores) or incorrectly done (1 score) or not done (zero). The total scores were 20 , then the total practice in temperature measurement was scoredcompetent $(\geq 85 \%)$ or incompetent $(<85 \%)$.

3- Administration and preparation of oral rehydration solution checklist, (The Rehydration Project, 2014), consisted of 10 steps which checked either done correctly (2 scores) or incorrectly done (1 score) or not done (zero). The total scores were 20, then the total practice in administration and preparation of ORS was scored competent $(\geq 85 \%)$ or incompetent $(<85 \%)$.

4- Insertion and rehydration of nasogastric tube checklist,(Skale, 2014), consisted of 13 steps which were checked either done correctly (2 scores) or incorrectly done (1 score) or not done (zero). The total scores were 26, then the total practice in insertion and rehydration of nasogastric tube was scored competent $(\geq 85 \%)$ or incompetent $(<85 \%)$.

5- Intravenous therapy checklist,(Skale, 2014), consisted of 10 steps which were checked either done correctly (2 scores) or incorrectly done (1 score) or not done (zero). The total scores were 20, then the total practice in intravenous (IV) therapy was scored competent $(\geq 85 \%)$ or incompetent $(<85 \%)$. 


\section{Nursing protocol for management of dehydration in children:}

It was developed by the researcher and prepared in the light of actual needs' assessment of the studied nurses who provided care to children with dehydration. A nursing protocol was developed in the form of a booklet in the light of different national and international references and was written in simple Arabic language. This nursing protocol was distributed to both nurses and parents of children.

\section{Ethical considerations:}

All nurses, children and parents' rights were secured. They were informed that the given information used only for research purpose. A clear, simple clarification of the study nature and its expected outcomes was explained to each study subject. The anonymity and confidentiality had been assured also. The study subjects had the right to withdraw from the study at any time. The research approval was obtained from Ethical Research Committee, Faculty of Nursing, Ain Shams University.

\section{Pilot study:}

A pilot study was carried out including $10 \%$ (five nurses, children and their children 'parents). The result of the data obtained from the pilot study helped in modification of the study tools, where some items were corrected, omitted and added as necessary. All the nurses and the children involved in the pilot study were excluded from the study sample.

\section{Field work:}

The actual field work was carried out over 6 month's period from the first week of December of 2014 up to the end of May 2015. The researcher was available in the study setting during morning shift 4 days/week (Saturday to Tuesday) to assess nurses' knowledge and actual practice.

The first phase (pre - nursing protocol of care for data collection): This phase started with nurse's interview with each study sample where the researcher introduced herself for them. At the beginning of the interview, the researchers present an orientation and explanation about nursing protocol for management of dehydration in children. Nurses were divided into small groups ranged between 3-5 nurses.

Each nurse was assessed, observed and evaluated using the study tools which filled by the researcher during providing care for the children with dehydration pre/post nursing protocol application. Time consumed for assessing each procedure taken nearly 20 30 minutes.

The child and their parents' assessment sheet was filled by the researcher based on medical file of child to take medical history or by their parents' interview within 20-30 minutes.

\section{The second phase (nursing protocol application):}

The nursing protocol intervention was implemented for 4weeks, four days per week. The protocol consisted of 10 sessions to be covered 8:25 hours. Theoretical part was taken over 2.25 hours for 5 sessions through 2 weeks, the duration of each session from 45-60 minutes including time of discussion. The session covered the following items: objectives and protocol schedule for nursing protocol, background about nursing protocol, parts of nursing protocol, content and plans of nursing protocol for dehydration, treatment plans of dehydration in children. While, practical part was taken over 6 hours for 5 sessions through 2 weeks, the duration of each session was 60 minutes including time of discussion. The session covered the following items: weighing the infant and the 
child, measurement axillary temperature, preparation and administration of oral rehydration solution, nasogastric insertion and administration of ORS by nasogastric tube, intravenous therapy. Including periods of discussion. At the beginning of the first session, an introduction about objectives of nursing protocol program was given, each session started with summary, feedback about previous sessions, simple words and Arabic language were used to suit the nurses' level of understanding. Different methods of teaching were used as lectures, demonstration and re-demonstration. Suitable teaching aids were prepared and used during the nursing protocol implementation such as real equipment, posters and pictures.

The implementation of nursing protocol was carried out at previously mentioned settings for nurses' knowledge and practice were evaluated pre nursing protocol to get a baseline assessment for nurses prior to the development of the nursing protocol and immediately post nursing protocol program by using the same tools to determine the effect of implemented nursing protocol program.

\section{The nursing protocol evaluation:}

Program appraisal was done by comparing the nurses' knowledge and skills, using questionnaire format sheet and observation checklists through pre / post of nursing protocol intervention.

\section{Administrative design:}

An official permission was obtained from the administrators of the study setting through a formal letter that was issued from the Dean of the Faculty of Nursing, Ain Shams University. An oral written approval to carry out the study was taken from each nurse and from the accompanying parents of children suffering from dehydration.

\section{Statistical analysis:}

The collected data were organized, tabulated, categorized and statistically analyzed by using computer program (SPSS) version. Data were presented in tables as numbers and percentage. Mean and standard deviation, Chi-square test and test were used to estimate the statistical significant difference between variables of the study. No Significance if $p>0.05$ and significance if $p$ $<0.05$.

\section{Results}

Table (1) shows that, distribution of the studied nurses according to their total knowledge regarding to total nursing protocol plans in management of dehydration (pre/post) $(\mathrm{n}=30)$. This table illustrated that, there was a statistically significant difference between pre and post implementation of nursing protocol $(\mathrm{t}=5.070 \& \mathrm{P}<0.001)$ was noted in relation to total knowledge about total nursing protocol plans in management of dehydration.

Table (2) shows that, distribution of the studied nurses according to their total knowledge regarding to methods of administration of ORS orally or through nasogastric tube(pre/post)(n=30).As noticed in this table, that there was a general improvement of nurses' knowledge post implementation of the nursing protocol compared to pre-its implementation with a statistically significant difference $(p<0.036)$.

Table (3) shows that, distribution of the studied nurses according to their practice in preparation \& administration of ORS (pre/post) $(\mathrm{n}=30)$. As regard to nurses' practice regarding to preparation \& administration of oral rehydration solution, it was observed from this table that, there was marked improvement in nurses' practice immediately post implementation of nursing protocol with a statistical significance difference $(\mathrm{p}<0.001)$ between pre and post implementation of nursing protocol. 
Table (4) shows that, distribution of the studied nurses according to their practice in intravenous therapy (pre/post) $(\mathrm{n}=30)$. This table illustrated that, there was a marked improvement in nurses' practice for intravenous therapy in addition to there was a statistical significance difference $(\mathrm{P}<0.001)$ between pre and post implementation of nursing protocol.

Table (5) shows that, relation between total knowledge of the studied nurses regarding pediatric dehydration and its nursing management protocols and their total practices regarding management of children(pre/post $)(n=30)$.It was clear that shows that there was no statistical significant difference between total knowledge of the studied nurses and their total practice pre implementation of nursing protocol $\left(\mathrm{X}^{2}=2.935 \& \mathrm{p}=0.087\right)$. While, there was a statistical significant difference between total knowledge of the studied nurses and their total practice post implementation of nursing protocol $\left(\mathrm{X}^{2}=13.500 \& \mathrm{p}=0.001\right)$.

Table (1): Distribution of the studied nurses according to their total knowledge regarding to total nursing protocol plans in management of dehydration (pre/post) $(n=30)$.

\begin{tabular}{|c|c|c|c|c|c|c|c|c|}
\hline \multirow{3}{*}{ Total Nursing protocol plans } & \multicolumn{4}{|c|}{ Pre } & \multicolumn{4}{|c|}{ Post } \\
\hline & \multicolumn{2}{|c|}{ Unsatisfactory } & \multicolumn{2}{|c|}{ Satisfactory } & \multicolumn{2}{|c|}{ Unsatisfactory } & \multicolumn{2}{|c|}{ Satisfactory } \\
\hline & $\mathbf{N}$ & $\%$ & $\mathbf{N}$ & $\%$ & $\mathbf{N}$ & $\%$ & $\mathbf{N}$ & $\%$ \\
\hline $\begin{array}{l}\text { Nursing protocol plans } \\
\text { of dehydration }\end{array}$ & 7 & 23.3 & 23 & 76.7 & 3 & 10.0 & 27 & 90.0 \\
\hline Plan A & 19 & 63.3 & 11 & 36.7 & 5 & 16.7 & 25 & 83.3 \\
\hline Plan B & 18 & 60.0 & 12 & 40.0 & 8 & 26.7 & 22 & 73.3 \\
\hline Plan $\mathrm{C}$ & 22 & 73.3 & 8 & 26.7 & 7 & 23.3 & 23 & 76.7 \\
\hline T-test\&(p-value) & & & & $070(<$ & $01 *)$ & & & \\
\hline
\end{tabular}

Table (2): Distribution of the studied nurses according to their total knowledge regarding methods of administration of ORS orally or through nasogastric tube (pre/post) $(n=30)$.

\begin{tabular}{|c|c|c|c|c|c|c|c|c|}
\hline \multirow{3}{*}{ Method of Administration: } & \multicolumn{4}{|c|}{ Pre } & \multicolumn{4}{|c|}{ Post } \\
\hline & \multicolumn{2}{|c|}{ Unsatisfactory } & \multicolumn{2}{|c|}{ Satisfactory } & \multicolumn{2}{|c|}{ Unsatisfactory } & \multicolumn{2}{|c|}{ Satisfactory } \\
\hline & No. & $\%$ & No. & $\%$ & No. & $\%$ & No. & $\%$ \\
\hline $\begin{array}{l}\text { Oral rehydration solution } \\
\text { (ORS). }\end{array}$ & 21 & 70.0 & 9 & 30.0 & 7 & 23.3 & 23 & 76.7 \\
\hline $\begin{array}{l}\text { Nasogastric rehydration tube } \\
\text { (NRT). }\end{array}$ & 18 & 60.0 & 12 & 40.0 & 9 & 30.0 & 21 & 70.0 \\
\hline t-test(p-value) & \multicolumn{8}{|c|}{$2.146(0.036 *)$} \\
\hline
\end{tabular}


Table (3):Distribution of the studied nurses according to their practice in preparation \& administration of ORS (pre/post) $(\mathrm{n}=30)$.

\begin{tabular}{|c|c|c|c|c|c|c|c|c|}
\hline \multirow{3}{*}{ Oral rehydration solution administration } & \multicolumn{4}{|c|}{ Pre } & \multicolumn{4}{|c|}{ Post } \\
\hline & \multicolumn{2}{|c|}{ Incompetent } & \multicolumn{2}{|c|}{ Competent } & \multicolumn{2}{|c|}{ Incompetent } & \multicolumn{2}{|c|}{ Competent } \\
\hline & No & $\%$ & No & $\%$ & No & $\%$ & No & $\%$ \\
\hline Explain procedure to mother. & 29 & 96.7 & 1 & 3.3 & 1 & 3.3 & 29 & 96.7 \\
\hline $\begin{array}{l}\text { Tell mother to wash hands with soap and } \\
\text { water. }\end{array}$ & 28 & 93.3 & 2 & 6.7 & 1 & 3.3 & 29 & 96.7 \\
\hline Tell mother to use FILTERED water & 29 & 96.7 & 1 & 3.3 & 1 & 3.3 & 29 & 96.7 \\
\hline Add water only. Do not add sugar. & 29 & 96.7 & 1 & 3.3 & 1 & 3.3 & 29 & 96.7 \\
\hline $\begin{array}{l}\text { Tell mother to put all the powder from one } \\
\text { packet into a clean cup. }\end{array}$ & 19 & 63.3 & 11 & 36.7 & 2 & 6.7 & 28 & 93.3 \\
\hline $\begin{array}{l}\text { Tell the mother to give at teaspoonful every } \\
1-2 \text { minutes for the infant. }\end{array}$ & 18 & 60.0 & 12 & 40.0 & 1 & 3.3 & 29 & 96.7 \\
\hline $\begin{array}{l}\text { Explain to the mother that she should mix } \\
\text { fresh ORS solution each day in a clean } \\
\text { container }\end{array}$ & 28 & 93.3 & 2 & 6.7 & 1 & 3.3 & 29 & 96.7 \\
\hline $\begin{array}{l}\text { Give the mother two ORS packet to give } \\
\text { the child }\end{array}$ & 27 & 90.0 & 3 & 10.0 & 2 & 6.7 & 28 & 93.3 \\
\hline If the child vomits, wait for 10 minute & 28 & 93.3 & 2 & 6.7 & 1 & 3.3 & 29 & 96.7 \\
\hline t-test (p-value) & & & & 6.215 & 0.001 & & & \\
\hline The total & 26 & 86.7 & 4 & 13.3 & 1 & 3.3 & 29 & 96.7 \\
\hline
\end{tabular}

Table (4):Distribution of the studied nurses according to their practice in intravenous therapy (pre/post) $(\mathrm{n}=30)$.

\begin{tabular}{|c|c|c|c|c|c|c|c|c|}
\hline \multirow{3}{*}{ Intravenous therapy } & \multicolumn{4}{|c|}{ Pre } & \multicolumn{4}{|c|}{ Post } \\
\hline & \multicolumn{2}{|c|}{ Incompetent } & \multicolumn{2}{|c|}{ Competent } & \multicolumn{2}{|c|}{ Incompetent } & \multicolumn{2}{|c|}{ Competent } \\
\hline & No & $\%$ & No & $\%$ & No & $\%$ & No & $\%$ \\
\hline Prepare the child & 29 & 96.7 & 1 & 3.3 & 0 & 0.0 & 30 & 100.0 \\
\hline $\begin{array}{l}\text { Explain the procedure to the } \\
\text { mother }\end{array}$ & 30 & 100.0 & 0 & 0.0 & 0 & 0.0 & 30 & 100.0 \\
\hline Washing hands & 28 & 93.3 & 2 & 6.7 & 0 & 0.0 & 30 & 100.0 \\
\hline Check the medication rights & 18 & 60.0 & 12 & 40.0 & 0 & 0.0 & 30 & 100.0 \\
\hline Check patency of IV & 21 & 70.0 & 9 & 30.0 & 0 & 0.0 & 30 & 100.0 \\
\hline Administer the solution & 2 & 6.7 & 28 & 93.3 & 0 & 0.0 & 30 & 100.0 \\
\hline $\begin{array}{l}\text { Solution label must be placed } \\
\text { on IV bag }\end{array}$ & 4 & 13.3 & 26 & 86.7 & 0 & 0.0 & 30 & 100.0 \\
\hline $\begin{array}{l}\text { Document the dosage, amount, } \\
\text { time, the child's response }\end{array}$ & 5 & 16.7 & 25 & 83.3 & 0 & 0.0 & 30 & 100.0 \\
\hline Wash hands & 20 & 66.7 & 10 & 33.3 & 0 & 0.0 & 30 & 100.0 \\
\hline t-test (p-value) & & & & 24.818 & 01*) & & & \\
\hline The total & 18 & 60.0 & 12 & 40.0 & 0 & 0.0 & 30 & 100.0 \\
\hline
\end{tabular}


Table (5):Relation between total knowledge of the studied nurses regarding pediatric dehydration and its nursing management protocols and their total practices regarding management of children with dehydration (pre/post) $(\mathrm{n}=30)$.

\begin{tabular}{|c|c|c|c|c|c|c|c|c|c|}
\hline \multirow{3}{*}{\multicolumn{2}{|c|}{ Total Practice }} & \multicolumn{8}{|c|}{ Total Knowledge } \\
\hline & & \multicolumn{2}{|c|}{ Unsatisfactory } & \multicolumn{2}{|c|}{ Satisfactory } & \multicolumn{2}{|c|}{ Total } & \multirow[b]{2}{*}{$\mathrm{X} 2$} & \multirow[b]{2}{*}{ p-value } \\
\hline & & No. & $\%$ & No. & $\%$ & No. & $\%$ & & \\
\hline \multirow{2}{*}{ Pre } & Incompetent & 15 & 46.7 & 8 & 30.0 & 23 & 76.7 & \multirow{2}{*}{2.935} & \multirow{2}{*}{0.087} \\
\hline & Competent & 2 & 10.0 & 5 & 13.3 & 7 & 23.3 & & \\
\hline \multirow{2}{*}{ Post } & Incompetent & 4 & 6.7 & 2 & 13.3 & 6 & 20.0 & \multirow{2}{*}{13.500} & \multirow{2}{*}{$<0.001 *$} \\
\hline & Competent & 1 & 10.0 & 23 & 70.0 & 24 & 80.0 & & \\
\hline
\end{tabular}

\section{Discussion}

The nursing protocol is a method for teaching nurses and designed for the independent education as an attempt to avoid any strains for acquired new information at any time. Moreover, implementation of nursing protocol has a positive effect on the nurses' knowledge and performance and improved the quality of nursing care given to the children with dehydration (Mohakhail, 2011).

Regarding nurses' knowledge about nursing protocol plans in management of dehydration in children, it was found that, the majority of nurses' had unsatisfactory knowledge related to plan A pre implementation of nursing protocol which improved immediately post implementation of nursing protocol. These findings were supported by (Masiha et al., 2015) \&(Levinea et al., 2015), who reported that the majority of nurses knew that children classified as no dehydration (Plan A) receive only expectant outpatient management, with instructions given to continue breastfeeding as appropriate, provide the child with a normal diet and encourage fluid intake.

Regarding nurses' knowledge about nursing protocol plans in management of dehydration in children, it was found that, the majority of nurses' had unsatisfactory knowledge related to plan $\mathrm{B}$ pre implementation of nursing protocol which improved immediately post implementation of nursing protocol. These findings were supported by (Farthing et al., 2013), who study acutediarrhea in children, reported that, the majority of nurses knew that children classified with some dehydration (Plan B) are rehydrated using ORS, an inexpensive but logistically intensive process.

Regarding nurses' knowledge about nursing protocol plans in management of dehydration in children, it was found that, the majority of nurses' had unsatisfactory knowledge related to plan $\mathrm{C}$ pre implementation of nursing protocol, compared with improved of them immediately post implementation of the nursing protocol. These findings were supported by (Sanders, (2012), who study diarrhea management knowledge and practices among providers in Benin, found that the majority of nurses knew that children with severe dehydration (Plan C) are resuscitated with intravenous fluids, which generally requires the child to be transferred to an inpatient department.

Regarding to nurses' knowledge about oral rehydration solution (ORS), it was found that, more than two thirds of the studied nurses didn't know definition of ORS pre 
implementation of nursing protocol, which improved significantly immediately post implementation of the nursing protocol. These findings were supported (Abdel-Aziz et al., 2016)\&(Francis et al., 2016 ), who study the impact of a community-based health and nutrition education on the management of diarrhea in an urban district, Cairo, Egypt, reported that, information regarding awareness of nurses about ORS. In the pre- intervention phase, more than two thirds of the nurses had heard about ORS, whereas in the post intervention phase, awareness about ORS increased significantly $(\mathrm{P}<0.036)$

Regarding to nurses' knowledge about nasogastric rehydration tube (NRT), the current study illustrated that, nearly two thirds of the studied nurses didn't know NRT pre implementation of nursing protocol, compared with improved of them immediately post implementation of the nursing protocol. These findings were supported by (Abdullah et al., 2014), who study nurses' knowledge and practices about administration of medications via nasogastric tube among critically ill patients, reported that, all of studied subject's knowledge levels as regards to administration of medication via NGT were unsatisfactory. This may be due to lack of hospital policy, no standard guidelines for administration of medication via nasogastric tubes.

Regarding to nurses' practice about critical points of preparation and administration of oral rehydration solution, it was observed that the highest percentage of nurses' practice related to the proper way for preparation and administration of oral rehydration solution were incompetent pre implementation nursing protocol, which compared with improved of them immediately post implementation of the nursing protocol. These findings weren't similar to the findings of the study done by (Onwukwea et al., 2016), who study evaluation of the use of oral rehydration therapy in the management of diarrhea among children under 5: knowledge, attitudes and practices of mothers/caregivers, mentioned that, the study participants were generally poor in their practice regarding ORS. This is because of administration of correctly prepared ORT is central to the effective and successful management of dehydration and the use of oral rehydration therapy is a proven intervention to prevent dehydration among children during episodes of diarrhea.

On investigating nurses' practice about critical points of intravenous therapy, the present study illustrated that, the highest percentage of nurses' practice related to check the medication rights, patency of IV, administer the solution and solution label must be placed on IV bag were incompetent pre implementation nursing protocol, which compared with improved of them immediately post implementation of the nursing protocol. These findings were similar to the findings of the study done by (Fonyuy, 2015), who mentioned that, most of the nurses had good skills about administering medication.

The current study showed that there was no statistically significant difference between total practice and total knowledge pre implementation of nursing protocol. While, there was a statistically significant difference between total practice and total knowledge post implementation of nursing protocol. This finding was supported with(Masiha et al., 2015), who study oral rehydration therapy; knowledge, attitude and practice (KAP) survey of Pakistani nurses, found that, a highly statistically significant relation with strongly positive correlation between mean scores of knowledge and practices of same nurses. This showed that those with increasing scores of knowledge in nurses associated with increased their scores of practices. 


\section{Conclusion}

In the light of the present findings, it can be concluded that nurses' knowledge and practices were significantly improved after implementation of the nursing protocol regarding management of dehydration in children. As a result, the nursing protocol was positively effective in the management of dehydration in children.

\section{Recommendations}

This study recommended to:

1. Further application of nursing protocols for better quality of care for children with dehydration.

2. Availability of standardized nursing protocols regarding management of dehydration in children in pediatric hospitals.

3. Replication of the study using a larger probability sample from different pediatric emergency departments

\section{References}

Keeley, P., Wolf, Z., Regul, L. and Jadwin, L. (2015): Effectiveness of standard of care protocol on pediatric patient satisfaction and perceived staff caring, clinical journal; 19(3), 352-360. DOI: 10.1188/15.CJON.352-360, available at: https://cjon.ons.org/cjon/19/3/effectivenes s-standard-care-protocol-patientsatisfaction-and-perceived-staffcaring\#sthash.vlI0QAxk.dpuf. Accessed at: 19 March 2015.

Chen, L., Hsiao, A., Melissa Langhan, M., Riera, A. and Santucci, K.A. (2011): Use of bedside ultrasound to assess degree of dehydration in children with gastroenteritis, academerg med; 17(10): 1042-1047.
American Academy of Pediatrics, (2015): Caring for your baby and young child: birth to age 5, 6th ed., Available at:https://www.healthychildren.org/Englis $\mathrm{h} /$ healthissues/injuriesemergencies/Pages/ dehydration.aspx. Accessed at: 1 December 2014.

World Health Organization, the Centers for Disease Control and Prevention (CDC), the American Academy of Pediatrics (AAP) and the European Society of Pediatric Gastroenterology and Nutrition (ESPGAN), (2011): The treatment of diarrhea: a manual for physicians and other senior health workers. Journal of pediatric gastroenterology and nutrition; 30(5):486-489.

Retezar, R., Bessman, E., Ding, R., Zeger, S. and McCarthy, M. (2011): The effect of triage diagnostic standing orders on emergency department treatment time. Annals of emergency medicine; 57(2):89-99.

Stauber, MA. (2013): Advanced nursing interventions and length of stay in the emergency department. Journal of emergency nursing; 39(3): 221225.Santosham, M., Chandran, A., Fitzwater, S., Fischer-Walker, C., Baqui, H.A. and Black, R. (2011): Progress and barriers for the control of diarrheal disease. The Lancet; 376(9734):63-67.

Yu, C., Lougee, D. and Murno, JR. (2011): Diarrhea and dehydration, Manual-06international, journal of critical care nurse; 24:87-88. Avialable at: https://www.aap. org/en-us/advocacyand-policy/aap-health initiatives/ children- anddisasters/ Documents/ MANUAL-06-internacional-2011.pdf. Accessed at: February 2014.

Bonilla-Felix, M., Parra, C., Dajani, T., Ferris, M., Swinford, RD. and Portaman, RJ. (2011): Changing patterns in 
pathology of dehydration $\mathrm{n}$ children. Pedint; 55(5):90-1885.

Harmon, S., Conaway, M. and Sinkin, R. (2013): Factors associated with emergency care setting follow up appointment compliance. Journal of clinical pediatrics; 52(7).

Pringle, K., Shah, S., Umulisa, I., Munyaneza, R., Dushimiyimana, J., Stegmann, K., Musavuli, J., Ngabitsinze, P., Stulac, S. and Levine, A. (2011): Comparing the accuracy of the three popular clinical dehydration scales in children with diarrhea, international journal of emergency medicine; 58(4):1865-1380.

Sayed, YN., El- Sayed, AM. andAbd ElFattah, SA. (2014): Effect of socioeconomic status on infectious diarrhea in egyptian children, international journal of nutrition and food sciences; 3(6): 519-525, available at: (http://www.

sciencepublishinggroup.com/j/ijnfs).

Accessed at: 30 October 2014.)

Cupta, p. (2011): Clinical methods in pediatrics, 1st ed., CBS publishers and distributors, new dehhi, Bangalore, pune (INDIA), Pp. 65-68.

Skale, N. (2014): Manual of pediatric nursing procedures, 1st ed., J.B. Lippincott Company, Philadelphia, New York, Pp.47-51.

The Rehydration Project, (2014): A manual for community educators. Available at: http//rehydrate.org/rehydration /index.html and food water and family health

Mohakhail, A., Morcela, D. and Kasel, F. (2011): Childhood dehydration, inform and res; 138:4624-31.
Masiha, SM., Khalid, A., Malik, B. and Ali, SM. (2015): Oral rehydration therapyknowledge, attitude and practice (KAP) survey of pakistani nurses, journal of rawalpindi medical college students supplement; 19(S-1):51-54

Levinea, A.C., Glavis-Blooma, J., Modia, P., Nasrinb, S., Regea, S., Chuc, C., Schmidc, C.H. and Alamb, N.H. (2015): Empirically derived dehydration scoring and decision tree models for children with diarrhea: assessment and internal validation in a prospective cohort study in dhaka, bangladesh, health scipract; 3(3): 405-418.

Farthing, M., Salam, M.A., Lindberg, G., Dite, P., Khalif, I. and Salazar-Lindo, E. (2013): Acute diarrhea in children: a global perspective. J clingastroenterol; 47(1): 12-20.

Sanders, E. (2012): Diarrhea management knowledge and practices among providers in Benin. SHOPS (strengthening health outcome through private sector) is funded by the U.S. agency for international development. USAID from amercian people. Available at: file:///C:/ Users/as/ Downloads/Results_Benin\%20Provider\% 20Survey.pdf. Accessed at: July 2014.

Abdel-Aziz, SB., Mowafy, MA. andGalal, YS. (2016): Assessing the impact of a community-based health and nutrition education on the management of diarrhea in an urban district, cairo, egypt, global journal of health science; 8(2):49; 2016ISSN 1916-9736 E-ISSN 19169744. Published by canadian center of science and education. Available at:www.ccsenet.org/gjhs. Accessed at: 12 July 2014.

Francis, H., Samhitha, J. and Indira, A. (2016): Knowledge on rehydration therapy, international journal of applied research; 2(5): 657-659. Accessed at: 19 May 2016. 
Abdullah, M., Mohammed, W. and Ismail, M. (2014): Nurses' knowledge and practices about administration of medications via nasogastric tube among critically ill patients, journal of education and practice;(5)1:92. Available at:www.iiste.org. Accessed at: 12 August 2014.

Onwukwea, S., Deventera, C. and Omolea, O. (2016): Evaluation of the use of oral rehydration therapy in the management of diarrhea among children under 5: knowledge, attitudes and practices of mothers/caregivers, South African family practice; 58(2):42-47.

Fonyuy, BF. (2015): Diarrhea in the underfives: constraints encountered by care providers in its of public health; 3(3):2.

Masiha, SM., Khalid, A., Malik, B. and Ali, SM. (2015): Oral rehydration therapyknowledge, attitude and practice (KAP) survey of pakistani nurses, journal of rawalpindi medical college students supplement; 